\title{
The Efficacy of the Organo-Zeolitic Bio-fertilizer
}

\section{Peter J Leggo*}

Department of Earth Sciences, University of Cambridge, UK

*Corresponding author: Peter J Leggo, Department of Earth Sciences, University of Cambridge, UK, Tel: 01223 333 462; E-mail: pjl46@cam.ac.uk

Rec date: July 22, 2014, Acc date: Oct 21, 2014, Pub date: Oct 23, 2014

Copyright: ( 2014 Leggo PJ, This is an open-access article distributed under the terms of the Creative Commons Attribution License, which permits unrestricted use, distribution, and reproduction in any medium, provided the original author and source are credited.

\begin{abstract}
The aim of this research is to evaluate the properties and benefits of using an organo-zeolitic fertilizer (biofertilizer) for the production of food crops and the vegetation of contaminated land. Apart from the ever increasing cost of chemical fertilizers their use over the last seventy or more years have had a deleterious effect on soil health. In contrast the bio-fertilizer, composed of organic waste and crushed zeolitic rock, containing Clinoptilolite and commonly Mordenite zeolite, functions biologically in sponsoring nitrification. Ammonium ions, provided from the degradation of the organic waste, are adsorbed to the zeolite mineral surface thus avoiding loss to the atmosphere by volatilization. Oxidation of the ammonium ions, by soil nitrifying micro-organisms, provides major and trace element nutrients. Analysis of pore water, from substrates amended with the bio-fertilizer, has shown that its electrical conductivity is orders of magnitude higher than that of pore water from un-treated substrates. This is reflected in the high ionic concentration of cations present, which covers a wide range of elements, providing essential major and beneficial trace-elements in the ionic state that are directly available for plant uptake. Further work has shown that without the organic component the degree of plant growth is greatly reduced and the converse applies in that the application of the organic waste without the crushed zeolitic rock again reduces plant growth. Many countries in the world have extensive deposits of zeolitic sediment, containing a high abundance of zeolite minerals, and the organic component, being animal or plant waste, is generally availability.
\end{abstract}

Keywords: Bio-fertilizer; Natural zeolite; Nitrification; Ionic state; Plant nutrition

\section{Introduction}

Zeolites are silicate minerals that have an unusual crystal structure. The structure contains open channels/pores in which cations and water molecules are captured and often loosely bound to the oxygen atoms that compose the channel walls $[1,2]$. Natural zeolites have two modes of formation: large crystals, often measured in centimeters, found precipitated from hydrothermal fluids that percolate through cavities (vugs) in the tops of lava flows. The other mode of formation is due to explosive volcanic eruptions which produce extensive clouds of ash composed in part of small glass shards. The fine particles drift away from the volcanic eruption centers and on falling into water are altered to crystalline minerals of which zeolites are commonly in high abundance; often reaching $80-90 \%$ of the rock. On uplift these sediments are often found as thick deposits that can be mined by open-cast procedures and it is this material that is used as the zeolitic component of the bio-fertilizer.

The agricultural use of natural zeolites has long been known but only in the last decade has soil microbiological activity been recognized as driving the bio-fertilizer - soil system. The first experience of the efficacy of a mixture of organic waste and crushed zeolitic tuff was pre-1995 when Professor H. Minato was asked to try and remediate the malodourous poultry waste accumulating at a farm in Japan. As the absorptive properties of zeolitic tuff were known it was suggested that local zeolitic tuff be used to dry the floor of the farm yard. This was very successful and it was decided to spread the now dry material on a nearby field. This had the effect of greatly enhancing plant growth. One of the first to realize the influence of such material on the soil microbial community was Professor TG
Andronikashvili and his colleagues at the Georgian Academy of Science, Tbilisi, Republic of Georgia [3]. The use of molecular biological technology to identify the soil micro-organisms has now shown ammonium oxidizing microbes to be responsible for oxidizing the ammonium ions, captured by the zeolitic component of the biofertilizer, to nitrite and finally to nitrate. During this process the enzymes that catalyse the reactions supply hydrogen ions as a byproduct [4]. These very reactive ions dissociate cations from the substrate providing nutritional elements, in an ionized state, that can be taken-up through the plant roots. Together with the major nutrients, nitrate, phosphate and potassium, these elements cover a large range of plant nutrients required for healthy plant growth. The source of phosphorus in the amended substrates is as an organophosphate present in the organic waste. Although it is uncertain how the phosphate is solubilized, it is known that the final stages occur through the action of phosphatase enzymes which are produced by the microbial population including both bacteria and fungi [5].

The chemical concentration of twenty nutritional elements in stems and leaves has been measured; using Brassica napus and Salix viminalis in pot experiments [6].

Close inspection of Table 1 reveals large differences between plants grown in amended and un-amended substrates which are plant specific. In the case of $B$. napus very large differences are seen in the concentrations of $\mathrm{Na}, \mathrm{K}, \mathrm{Ca}$, and $\mathrm{Mo}$ in which these elements have greatly increased values in plants growing in the amended substrates. Also large decreases are found in $\mathrm{Al}, \mathrm{Si}, \mathrm{P}, \mathrm{Zn} \mathrm{As}, \mathrm{Sr}$, and $\mathrm{Pb}$ in plants growing in the amended substrates. Similar variations are seen in the data of $S$. viminalis but are quite different to those of $B$. napus. Considering the high degree of growth enhancement in plants growing in the amended substrates it is thought that the mobilisation of the pore water, providing chemical nutrients in an ionized state, 
Page 2 of 4

influences plant uptake. It therefore appears that ion-homeostasis plays a leading role. However, much more work will be required to understand this behaviour on an element by element basis and it is obvious that both plant type and substrate chemistry must influence plant growth in the amended substrate.

\begin{tabular}{|l|l|l|l|l|}
\hline \multirow{2}{*}{} & \multicolumn{2}{|l|}{ Oil Seed Rape (B.Napus) } & \multicolumn{2}{l|}{ Osier Willow (Salax Viminalis) } \\
\cline { 2 - 5 } & Column 1 & Column 2 & Column 1 & Column 2 \\
\hline $\mathbf{B}$ & $22.7 \pm 2.5$ & $33.5 \pm 3.1$ & $90.2 \pm 10.6$ & $83.7 \pm 17.5$ \\
\hline $\mathbf{N a}$ & $392 \pm 72.8$ & $1537 \pm 173$ & $1575 \pm 258$ & $656 \pm 14$ \\
\hline $\mathbf{M g}$ & $3340 \pm 260$ & $3603 \pm 172$ & $2626 \pm 176$ & $3126 \pm 201$ \\
\hline $\mathbf{A l}$ & $2900 \pm 150$ & $21.3 \pm 10.2$ & $296 \pm 40.6$ & $139 \pm 27.7$ \\
\hline $\mathbf{S i}$ & $2491 \pm 16.3$ & $889 \pm 100$ & $1019 \pm 37.3$ & $878 \pm 30.3$ \\
\hline $\mathbf{P}$ & $8504 \pm 255$ & $2658 \pm 95.1$ & $3203 \pm 525$ & $4991 \pm 328$ \\
\hline $\mathbf{S}$ & $7719 \pm 192$ & $5643 \pm 279$ & $3815 \pm 363$ & $5955 \pm 377$ \\
\hline $\mathbf{K}$ & $8007 \pm 885$ & $18912 \pm 630$ & $16796 \pm 2878$ & $20636 \pm 3798$ \\
\hline $\mathrm{Ca}$ & $6595 \pm 364$ & $13521 \pm 700$ & $9597 \pm 1317$ & $20444 \pm 3564$ \\
\hline $\mathbf{M n}$ & $63 \pm 0.6$ & $78 \pm 3.6$ & $80 \pm 6.0$ & $297 \pm 77$ \\
\hline $\mathrm{Co}$ & $0.74 \pm 0.02$ & $0.24 \pm 0.01$ & $0.34 \pm 0.06$ & $0.26 \pm 0.07$ \\
\hline $\mathbf{N i}$ & $2.8 \pm 0.12$ & $1.2 \pm 0.06$ & $0.95 \pm 0.09$ & $0.62 \pm 0.12$ \\
\hline $\mathbf{C u}$ & $35 \pm 0.23$ & $3.5 \pm 0.05$ & $4.1 \pm 0.50$ & $6.7 \pm 0.30$ \\
\hline $\mathbf{Z n}$ & $795 \pm 40.3$ & $43 \pm 1.6$ & $50.2 \pm 10.5$ & $322 \pm 64.4$ \\
\hline $\mathbf{A s}$ & $0.72 \pm 0.04$ & $0.22 \pm 0.01$ & $0.38 \pm 0.04$ & $0.15 \pm 0.04$ \\
\hline $\mathrm{Sr}$ & $31 \pm 1.0$ & $14 \pm 1.0$ & $59.1 \pm 4.39$ & $108 \pm 20.5$ \\
\hline $\mathbf{M o}$ & $0.4 \pm \mathrm{n.d}$ & $2.1 \pm 0.10$ & $0.63 \pm 0.08$ & $1.6 \pm 0.24$ \\
\hline $\mathbf{C d}$ & $1.7 \pm 0.03$ & $0.34 \pm 0.01$ & $0.35 \pm 0.08$ & $1.7 \pm 0.35$ \\
\hline $\mathbf{C s}$ & $0.79 \pm 0.01$ & $0.16 \pm 0.01$ & 0.060 .01 & $0.13 \pm 0.01$ \\
\hline $\mathbf{P b}$ & $3219 \pm 9.22$ & $5.1 \pm 0.66$ & $30.8 \pm 14.6$ & $16.8 \pm 6.90$ \\
\hline
\end{tabular}

Table 1: Element concentrations $\left(\mathrm{mg} \mathrm{kg}^{-1}\right)$ in leaves; Columns 1 show data for plants grown in un-amended sulphide mine waste and columns 2 data for plants grown in amended mine waste; All plants were grown in pots under contemporary greenhouse conditions.

\section{Plant Experiments}

Over the last decade many plant experiments have been performed, mostly in pots under greenhouse conditions. Early work with Spring Wheat (Triticum aestivum L., cv. Paragon) demonstrated that plants grown in soil amended with the bio-fertilizer had a marked effect on growth. This work defined the optimum conditions for the organozeolitic-soil system and it was found that plants growing in these conditions consistently out-performed those growing in soil amended with organic material without the zeolitic component and also those growing in soil amended with an artificial chemical fertilizer [7]. This study formed the basis of many other plant experiments, which has resulted in the current hypothesis. The analysis of carefully controlled aqueous leachate samples have led to an understanding of the degree of ionic mobilization of the pore water of the amended substrates, which have electrical conductivities generally an order of magnitude greater than those of the un-amended substrates [7]. This together with the stimulation of nitrification caused by the microbial oxidation of the ammonium ions captured by the zeolitic component [8] caused the growth enhancement seen throughout the plant experiments. Typical examples of growth enhancement seen in plants growing in the bio-fertilizer amended substrates are shown in a study of plants growing in coal waste [9].

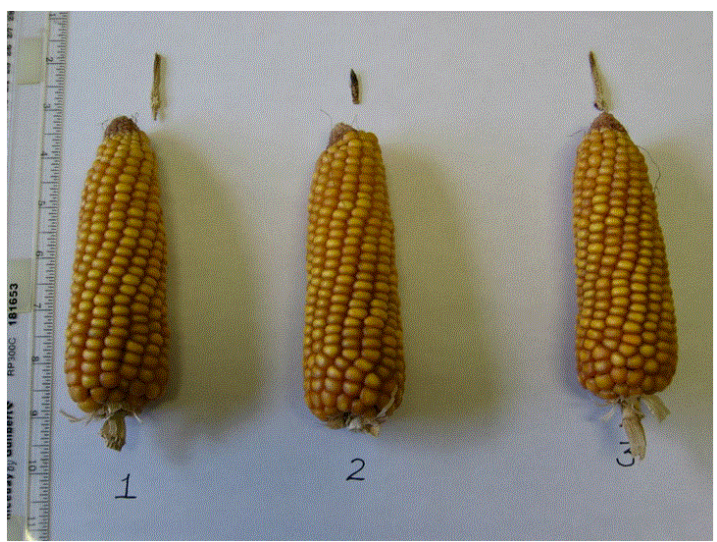

Figure 1: Comparison of Maize ears from plants growing in unamended coal waste, shown above those grown in amended coal waste.

Plants were grown in triplicate, in pots under greenhouse conditions. The very large difference is thought to be due to the availability of nutrient elements from the amended coal waste although plant disease cannot be ruled out for causing the poor result of plants growing in the un-amended coal waste (Figure 1).

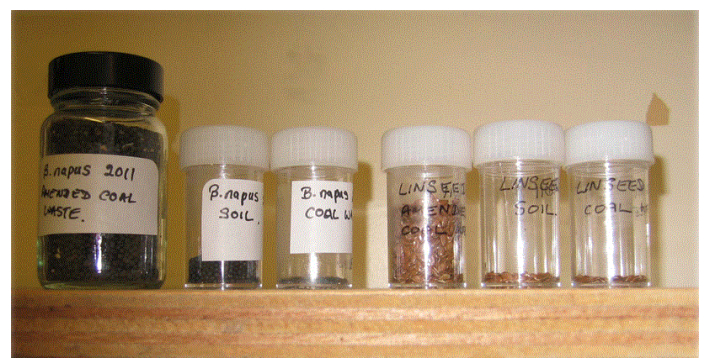

Figure 2: Seed yields at harvest from pot experiments with Oil Seed Rape (Brassica napus) and Linseed (Linum usitatissimum) grown under greenhouse conditions in three substrates: bio-fertilizer amended coal waste, soil from the Cambridge University Botanic Garden describer in Leggo [7] and unamended coal waste.

The seed yields represent bulk amounts from triplicate replications and show a very great difference between the plants growing in the amended coal waste, left hand side and those from the un-amended substrates, center and right hand. It is interesting to note that the differences are similar in both plant species (Figure 2). 
In the work with coal waste controls were made using $x$ growing in nine different substrates. These results are from in Leggo [9] published in the International Journal of Environment and Resource (IJER) and are shown here as Figure 3.

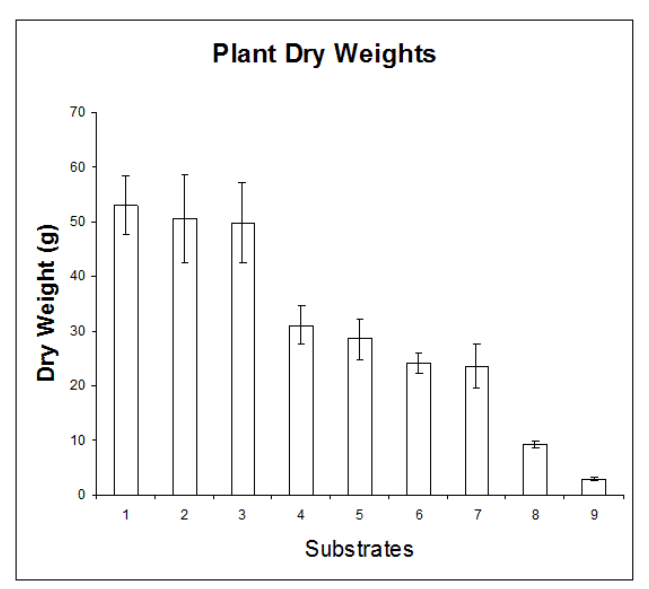

Figure 3: Extended controls; plant grown in 2 Litre pots, replicated three times. Dry weights are averages of the replicates; error bars are standard mean deviations. Substrates: (1) Coal Waste + Biofertilizer + Lime; (2) Coal Waste + Garden Soil + Poultry Manure + Activated Charcoal; (3) Coal Waste + Biofertilizer Lime; (4) Coal Waste + Poultry Manure; (5) Garden Soil; (6) Coal Waste + Zeolitic Tuff; (7) Garden Spoil + Poultry Manure; (8) Coal Waste + Garden Soil + Zeolitic Tuff; (9) Coal Waste.

Two facts become apparent from inspecting the data. It can be seen that plants grown in substrates 1,2 and 3 have much higher dry weights than the others and are within the experimental error of each other. Two of these substrates, 1 and 3 , contain zeolitic tuff differing only in the addition of lime; the lime being used to increase the $\mathrm{pH}$ value of the substrate pore water in order to preserve the function of the ammonium oxidizing micro-organisms. In this case little difference is seen. Whereas, substrate 2 contains activated charcoal which replaces, by volume, the zeolitic tuff. The dry weight of plants grown in this substrate is within the experimental error of the other two substrates. Activated charcoal is micro porous and known to absorb ammonium ions [10]. It is therefore not surprising that it functions in a similar way to zeolitic tuff. The zeolite being a framework silicate is more resistant to soil particle erosion and is therefore to be preferred. The second fact to emerge is that both organic and zeolitic components must be present to achieve high growth enhancement. This fact is self-evident from the former work although zeolitic tuff alone will retain soil moisture which is beneficial in dry climates.

\section{Microbiological Studies}

In the early stages of this work it was found that DNA could not be recovered from ammonium oxidizing micro-organisms that are assumed to be present and sponsor nitrification. The systems investigated were plant pot substrates amended with either the biofertilizer or just manure. The technical details are not reported as they will be published in a later paper. The first attempt to look for ammonium oxidizing microbial populations, either bacteria and/or archaeal prokaryotes, was conducted with a bio-fertilizer that had been stored for several years. After the first un-successful attempts it was realised that the available ammonium ions had been oxidised in the first two to three months of preparing the bio-fertilizer. A second time-course experiment was repeated using a fresh batch of biofertilize and DNA was then successfully recovered from the amended soil after sixty days. This interval was observed, in earlier work, as that at which the capture of ammonium ions by the zeolite reached a peak [8] but its significance, regarding the present micro-biological work, was not initially appreciated. Dilutions of the extracted soil DNA were used as templates in PCR reactions utilising primers targeted to conserve portions of the ammonium oxidising genes [11]. PCR products were only detectable for the primers directed towards archaea which were then cloned into a suitable vector to enable sequencing of individual clones for the potential identification of soil micro-organisms. BLAST analysis showed clones that closely matched three uncultured crenarchaeote clones: AW-L-26 ammonium monooxygenase subunit A (amo A) gene, 99\% of the sequences match, P2-26 ammonium mono-oxygenase subunit A (amoA) gene, 99\% of the sequences match and AOA-AM120-7 again $99 \%$ of the sequences match. Although primers targeted to conserve portions of ammonium oxidising bacteria, none were found. This observation is consistent with other work that finds that prokaryotes from the kingdom Archea, the Crenarchae, are more abundant in soils than their bacterial counterparts [12]. This is not to say that more detailed work on the microbial study of soils amended with the bio-fertilizer would not discover the presence of bacterial nitrifiers.

\section{Conclusion}

Over a period of ten to fourteen years plant experiments, mostly in pots under greenhouse conditions, have consistently demonstrated the efficacy of the organo-zeolitic bio-fertilizer. Enhanced growth due use of the bio-fertilizer has been shown to depend on the bio-fertilizer providing an adequate supply of major, minor and beneficial trace elements. In sponsoring nitrification the enzyme reactions, producing hydrogen ions, cause a high degree of ionization of cations from the substrate, which is indicated by an order of magnitude increase in the electrical conductivity of the amended substrate pore water relative to that of the un-amended substrate. Chemical analysis of leaves and stems show large differences in uptake between plants grown in substrates, with and without the bio-fertilizer. It is envisaged that the high degree of ionic mobility of the amended substrate allows plants to be more selective in their uptake controlled by ion-homeostasis resulting in enhanced growth.

\section{Acknowledgement}

I would like to thank the Department of Earth Sciences, Institute of Biotechnology and the Botanic Garden of the University of Cambridge, for their support over many years and for the facilities that were made available. Funding over the last three year by Stiftung Energieforschung Baden -Württemberg is greatly appreciated; without which the recent research could not have been done. The molecular biological analysis was performed by Dr. David. M.D. Bailey whose analytical skills and input in other areas of the work are highly appreciated.

\section{References}

1. Ball AS (2006) Energy Inputs in Soil Systems. Biological Approaches to Sustainable Soil Systems, Taylor \& Francis, Boca Raton, London, New York: 79-89. 
2. Dyer A (1988) An introduction to Zeolite Molecular Sieves . John Wiley and Sons Ltd., London: 1-3.

3. Andronikashvili TG, Tsitsishvili GV, Kardava M, Gamisonia M (1999) The effect of organo-zeolitic fertilizer on microbial landscape of soil Izv.Acad.Sci.Georgia 25: 243-252.

4. Robertson GP, Groffman PM (2007) Nitrogen Transformations. In: Soil Microbiology, Ecology and Biochemistry 3: 341-364.

5. Plante AF (2007) Soil Biochemical Cycling Of Inorganic Nutrients and Metals. In: Soil Microbiology, Ecology, and Biochemistry 3: 391-400.

6. Leggo PJ, Ledésert B, Day J (2010) Organo-zeolitic treatment of mine waste to enhance the growth of vegetation. Eur. J. Mineral 22: 813-822.

7. Leggo PJ, Ledésert B, Christie G (2006) The role of clinoptilolite in organo-zeolitic-soil systems used for phytoremediation. Sci Total Environ 363: 1-10.
8. Leggo PJ, Ledésert (2009) The stimulation of nitrification in an organically enriched soil by zeolitic tuff and its effect on plant growing. Annals of Agrarian Sci 7: 9-15.

9. Leggo PJ (2013) Enhancing the growth of plants on coal waste using a biological fertilizer. Inter Jour Eviron and Resource 2: 59-66.

10. Asada T, Ohkubo T, Kawata K, Oikawa K (2006) Ammonia Adsorption on Bamboo Charcoal with Acid Treatment. Jour Health Sci 52: 585-589.

11. Hansel CM, Fendorf S, Jardine PM, Francis CA (2008) Changes in bacterial and archaeal community structure and functional diversity along a geochemically variable soil profile. Appl Environ Microbiol 74: 1620-1633.

12. Leininger S, Urich T, Schloter M, Schwark L, Qi J, et al. (2006) Archaea predominate among ammonia-oxidizing prokaryotes in soils. Nature 442: 806-809. 